\title{
$\$$ Research Square \\ Clean Energy Utilization Technology in the Transformation of Urban Existing Residence in China
}

\section{Li Zhao}

China Academy of Building Research

\section{Wei Chen}

North China University of Science and Technology

Qiong Li ( $\square$ hdliqiong@163.com )

North China University of Science and Technology https://orcid.org/0000-0001-9199-9865

\section{WeiWei Wu}

China Academy of Building Research

\section{Research}

Keywords: urban existing residence, energy-saving transformation, clean energy Substitution, climate region, Ridge regression analysis, STIRPAT Model

Posted Date: August 4th, 2020

DOI: https://doi.org/10.21203/rs.3.rs-50654/v1

License: @ (i) This work is licensed under a Creative Commons Attribution 4.0 International License. Read Full License

Version of Record: A version of this preprint was published at International Journal of Coal Science \& Technology on May 20th, 2021. See the published version at https://doi.org/10.1007/s40789-021-00417-5. 


\section{Abstract}

Clean energy substitution technology of existing residential buildings in cities is an inevitable choice for sustainable development and low-carbon ecological city construction. In this paper, the current status of energysaving renovation and renewable energy application of existing residential buildings in various cities in China is summarized by using statistical analysis method. According to different climatic zones of existing urban areas, the production and consumption of conventional energy (e.g. electricity, gas) and new energy (e.g. solar energy and air energy) are analyzed, and the energy consumption of buildings in existing urban residential areas is analyzed based on STIRPAT model principle. The influencing factors are modeled and analyzed quantitatively. The function relationship between energy consumption of existing residential buildings and influencing factors is analyzed by Ridge Regression with $\mathrm{R}$ software. The research results show that the areas with energy-saving modification area of existing buildings in China exceeding 10 million $\mathrm{m} 2$ by 2018 include: Xinjiang, Inner Mongolia and Shandong Province; based on data analysis of 2015-2017 in China with different climatic zones, the nuclear power generation capacity in hot summer and warm winter areas is ahead of other areas and the power generation capacity is increasing year by year; the wind power and solar power generation capacity in cold areas and cold areas is comparable. Strong and power generation also increases year by year; the proportion of clean energy generation in total power generation in each region is still small; the annual power generation of clean energy in each region is positively related to the total power generation. Based on STIRPAT model analysis, compared with 2009, urban residential energy consumption increased by $43.6 \%$ in 2016 .Natural gas-based clean energy has also increased from $7.9 \%$ to $13.4 \%$.But still cannot meet the demand of energy consumption of urban residential. The research results can provide basic data support for planning and implementation of clean energy upgrading and transformation system in existing urban residential areas in China.

\section{Introduction}

Energy shortage and carbon dioxide emission are increasingly prominent with development of China's economy [1]. In the current context, the level of resource consumption and the negative impact on environment are on the high side because of the growing city scale of urban residential area, the lack of foresight in urban residential planning [2], imperfect functional facilities, defects in existing construction technology [3] and so on, which aggravate current energy shortage and carbon dioxide emission like other industries. According to the energy development target announced by the State Council. The total primary energy consumption will be controlled at about 4.8 billion tce (tons of coal equivalent) by 2020 , non-fossil energy accounts for $15 \%$ of total primary energy consumption. China's revolutionary strategy on energy, production and consumption (2016-2030) [4] proposed that by 2030 , the demand for new energy mainly relied on clean energy, and the proportion of nonfossil energy to generate electricity was $50 \%$. Looking forward to 2050 , non-fossil energy accounted for more than half of primary energy consumption. In the future, China has a clear strategic goal and direction to replace fossil energy with clean energy, For the existing urban residential areas, clean energy alternative technologies mainly include the research on the key technologies of renewable energy utilization and cold and heat sources in existing buildings, and the research on clean power system and gas application technology of existing buildings. In recent years, China has successively issued national, industry and group standards and technical specifications. These effectively promote the renovation of existing buildings [5-9], but there is a lack of 
applicable standards for the renovation of existing urban residential areas. The transformation of clean energy to existing urban residential areas is how to achieve standardization and large-scale.

In the process of coping with climate change and changing economic development mode, low-carbon development of cities has become an important choice for all countries in the world to achieve sustainable development [10]. In 2004, the mayor's energy strategy issued in London, UK, established low-carbon as the future development direction [11]. In 2007, the mayor's energy strategy and action plan to deal with climate change were formulated under the title of "act today, wait for the future". Subsequently, the mayor's energy strategy amendment and 2010 were successively issued In the London climate change mitigation and energy strategy of, not only put forward emission reduction targets, but also analyzed 147 action measures mainly aimed at the energy sector, transportation sector and construction sector [12]. Stockholm, Sweden, has planned a zero carbon city in 2050 and formulated the fifth environmental plan (2008-2011) [13]. Seoul, South Korea, has paid attention to the synergistic effect of environmental protection, climate change and economic growth since the start of climate change action. In 2009, Seoul municipal government issued the low carbon green growth plan, which aims to achieve $40 \% \mathrm{CO}_{2}$ emission reduction by 2030 , and proposed the low carbon city development roadmap [14]. Denmark plans to get rid of its dependence on fossil energy and use renewable energy $100 \%$ by 2050 [15].

The energy consumption of urban residential buildings in China mainly includes the energy consumption of urban heating in the north, urban residential buildings and the air conditioning in the whole country [16-17]. The total energy consumption of buildings in the heating area of northern China is large, 2-3 times higher than that in the European Union countries with the same climate, more than twice the current $50 \%$ energy-saving standard; the proportion of energy-saving buildings in cities and towns is very low [18]. China's residential airconditioning energy consumption is far lower than that of the United States. Based on a detailed investigation of typical residential buildings in China and the United States, it is found that this huge energy consumption is mainly caused by "part time and part space" air conditioning [19]. Further investigation shows that the difference of dozens of times is not correlated with the economic income of each household, but is negatively correlated with age [20]. The reason lies in the difference of life mode, which leads to the difference of usage mode and energy consumption.

The demand for alternative technologies of clean energy in existing urban residential areas is a new requirement for the development of ecological civilization in China's urbanization. In this paper, statistical analysis method is used to summarize the current situation of energy-saving transformation and renewable energy application in existing urban residential areas in China. According to the different climate zones of existing urban areas, the production and consumption of conventional energy (such as electricity, gas) and new energy (such as solar energy and air energy) are analyzed, and the energy consumption of existing urban residential buildings is analyzed based on STIRPAT model The model of influencing factors is established for quantitative analysis, and ridge regression analysis is carried out for the functional relationship between building energy consumption and influencing factors in existing residential areas with $\mathrm{R}$ software.

\section{Materials And Methods}

\subsection{Survey and research process}


The existing urban residential areas are divided according to different climate region. Investigate the types and quantity of conventional energy (such as electricity, gas) and clean energy (such as solar energy, air energy) in these regions. Collect their outdoor environment and relevant data, and analyze their clean energy potential. Furthermore, define the important factors in the prediction model of clean energy efficient utilization strategy of existing urban residential areas. The survey and research process are shown in Fig. $2-1$.

\subsection{Data analysis method}

\subsubsection{Data map and climate division of China}

Using data map to analyze and display location related data is more clear and intuitive than in Excel. The purpose of dividing the building area by climate is to adapt the building to local conditions. In the General principles for design of civil buildings, the climate area of buildings in China is divided into seven main climate regions. In this paper, it is simplified to five climatic regions, and divide the distribution of clean energy according to the region. As shown in the Fig. 2-2.

\subsubsection{Ridge regression analysis}

In the 1970s, Ehrlich, an American scholar, proposed the IPAT ( $\mathrm{I}$ impact, $\mathrm{P}=$ population, $\mathrm{A}=$ fluency, $\mathrm{T}=$ Technology) equation to express the quantitative relationship between economic growth and resources and environment. Later, the above formula has been widely used in various fields [21-22], and at the same time, it shows certain limitations because of its few influencing factors [23-24] built STIRPAT model on the basis of IPAT model to supplement this deficiency, it is shown as:

$I=a P^{b} A^{c} T^{d} e$

Because it is a nonlinear model. Take logarithm on both sides of the model equation.it is shown as:

$\ln l=\ln a+b \ln P+c \ln A+d \ln T+\ln e$.

where in (2-2), I: energy consumption; P: population; A: economic development level; T: science and technology. A: model coefficient; $b, c$ and $d$ : the driving indexes of population, economy and science respectively; e is the model error.)

The model is revised by York [25] et al., and driven index data is obtained by statistical regression to support model prediction and analysis. STIRPAT model not only retains the relationship between driving forces in IPAT model, but also takes population, economy, technology and other driving forces as the main factors affecting the change of environmental pressure [26].

With STIRPAT principle of the model is to establish a model for quantitative analysis of the influencing factors of building energy consumption in existing urban residential areas, and to conduct ridge regression analysis on the model with $\mathrm{R}$ software. The purpose is to find out the relationship between the total urban population, urban per capita domestic energy consumption, GDP, energy consumption per unit GDP, the proportion of clean energy in terminal consumption and the existing urban residential building energy consumption City building energy conservation and emission reduction provides better strategies. 
The main influencing factors of urban residential energy consumption are total population, per capita energy consumption, GDP and energy consumption per unit of GDP. In this paper, the proportion of clean energy in the terminal energy consumption is added. Based on the model principle, the above five elements are taken as independent variables, and the existing urban residential energy consumption is taken as dependent variable to establish a model to analyze the contribution degree of independent variables and the development trend of clean energy, so as to provide better strategies for the improvement and transformation of energy conservation in the existing urban residential areas. The regression of the model is obtained by ridge regression analysis with $\mathrm{R}$ software. Ridge regression is a kind of biased estimation regression method for collinear data analysis. In essence, it is an improved least square estimation method. By giving up the unbiasedness of the least square method, it is more practical and reliable to obtain the regression coefficient at the cost of losing part of the information and reducing the accuracy. $R$ software is a set of international general and complete data processing, calculation and mapping software system. The R language used is a branch of s language, which was born around 1980. It is widely used in the field of statistics.

\section{Results}

\subsection{The current situation of energy-saving transformation of urban existing residential area}

The construction area of old residential area in 31 provinces was 3.491 billion $\mathrm{m} 2$, of which the construction area of old residential area in the severe cold region and cold region was 151,165.9 million $\mathrm{m}^{2}$ before August 2015. After the large-scale application and promotion of project achievements, taking energy saving and emission reduction as an example, according to the conservative calculation, the transformation amount of old residential areas in cold areas is only $10 \%$ of the existing old residential area in the severe cold region and cold region, the goal to reduce the building energy consumption ratio set as $10 \%$ compared with the guidance value, 600,000 tons of standard coal can be saved annually, 1.5 million tons of $\mathrm{CO}_{2}$ can be reduced, 45,000 tons of SO2 can be reduced, 400,000 tons of carbon dust can be reduced, economic benefits and ecological efficiency can be achieved. Meanwhile, it significantly improves the livability level of existing urban residential areas.

According to the '13th Five-Year'plan for renewable energy development [27],issued by the NDRC in December 2016 , by 2020 , the total annual utilization of renewable energy will be 730 million tce, including the utilization of commercial renewable energy will be 580 million tce. By the end of 2017, the installed capacity of electric power in China was 1.78 billion kilowatts, of which the installed capacity of renewable energy power generation reached about 650 million kilowatts, increasing from 33.1\% in 2015 to 36.6\% in 2017. Wind power and solar power generation account for more than $10 \%$ of the power generation in Inner Mongolia, Gansu, Qinghai and other provinces, becoming an important new power source.

From the Retrofitting of Existing Buildings Yearbook of 2018 [28], the statistics of energy-saving renovation area of existing residential buildings in China during 2017-2018 are shown in Fig. 3 - 1. In order to promote the revolution of energy production and consumption, promote the construction of ecological civilization, and give full play to the role of renewable energy in adjusting the energy structure and protecting the environment, the National Energy Administration organized various regions to prepare the development plan of new energy demonstration cities and new energy application demonstration industrial parks. The number of key 
development and utilization of renewable energy demonstration projects recommended by new energy demonstration cities in each province is shown in Fig. 3 - 2. In different cities, the advantages of energy resources are different. The renewable energy mainly considered for development includes solar photovoltaic and heat utilization, shallow geothermal energy, biomass energy (waste power generation, etc.), wind power generation, air energy, marine energy, hydropower, etc.

\subsection{Energy load of urban existing residential areas}

According to the statistical method of China Building Energy Conservation Association for the energy consumption of existing urban residential buildings, the energy consumption of urban residential buildings is mainly composed of the electricity consumption of household appliances and the consumption of natural gas, which is related to the level of urban development, the level of energy technology, the mode and concept of energy consumption of residents. The per capita energy consumption reflects the basic energy consumption of urban residents, which is positively related to the energy consumption of urban residential buildings.

From Fig. 3-3,3-4, it can be seen that the per capita usage of electricity and natural gas is increasing year by year, while the per capita usage of coal is decreasing year by year. From 2009 to now, the per capita use of natural gas has increased by $142.4 \%$. The per capita energy consumption of the whole country and cities is increasing year by year, and the per capita energy consumption of the cities is higher than that of the whole country, but the gap decreases year by year. Until the first time in 2017, the per capita energy consumption of the whole country is higher than that of the cities. It can be seen that energy-saving transformation of urban buildings and utilization of clean energy technology have achieved initial results.

Analysis of Fig. 3-5 shows that coal is the main source of fossil energy consumption in different region, while electricity and natural gas consumption in cold region is the most in each region.

\subsection{Regression analysis of urban residential energy consumption}

According to the above principle of STIRPAT model, the energy consumption model of urban buildings is established as shown in Fig. 3-6 Regression analysis is carried out with data from 2009 to 2016. Specific data are obtained from CHINA ENERGY STATISTICAL YEARBOOK 2018 [29], Statistical yearbook of urban and rural construction in China 2018.Beijing: China [30], 2012-2018 Annual Research Report on China's Building Energy Consumption. Beijing: China [31], as shown in Table $3-1$. 
Table 3-1

Data for the model

\begin{tabular}{|c|c|c|c|c|c|c|}
\hline year & $\begin{array}{l}\text { Energy } \\
\text { consumption } \\
\text { of urban } \\
\text { residential } \\
\text { area } \\
\text { (104tce) }\end{array}$ & $\begin{array}{l}\text { Total } \\
\text { urban } \\
\text { population } \\
(104)\end{array}$ & $\begin{array}{l}\text { Gross } \\
\text { Domestic } \\
\text { Product } \\
\text { (108yuan) }\end{array}$ & $\begin{array}{l}\text { Energy } \\
\text { consumption per } \\
\text { unit of GDP } \\
\text { (104yuan/104tce) }\end{array}$ & $\begin{array}{l}\text { Urban per } \\
\text { capita } \\
\text { energy } \\
\text { consumption } \\
(10-4 t c e)\end{array}$ & $\begin{array}{l}\text { Proportion of } \\
\text { clean energy in } \\
\text { end energy } \\
\text { consumption(\%) }\end{array}$ \\
\hline 2009 & 23600 & 64512 & 349081 & 1.16 & 328 & 7.9 \\
\hline 2010 & 24300 & 66978 & 413030 & 0.88 & 320 & 9 \\
\hline 2011 & 25300 & 69079 & 489301 & 0.86 & 331 & 9 \\
\hline 2012 & 26800 & 71182 & 540367 & 0.83 & 344 & 9.9 \\
\hline 2013 & 28800 & 73111 & 595244 & 0.79 & 357 & 10.7 \\
\hline 2014 & 30100 & 74916 & 643974 & 0.76 & 364 & 11.7 \\
\hline 2015 & 32000 & 77116 & 689052 & 0.63 & 377 & 12.3 \\
\hline 2016 & 33900 & 79298 & 743586 & 0.6 & 395 & 13.4 \\
\hline
\end{tabular}

Firstly, multiple linear regression is performed on the data, and the multicollinearity of the data is obtained by Klein discriminant method, which is not explained in detail here. Therefore, multiple linear regression cannot be used, ridge regression is used as mentioned above. Ridge regression is a biased estimation regression method which is specially used in the analysis of collinear data. After running, the ridge trace is shown in Fig. 3-7

According to the value principle of $\mathrm{K}$ value (lambda value), this paper takes $\mathrm{K}$ value (lambda value) recommended by $\mathrm{R}$ software. $\mathrm{K}=0.01215678$, The regression equation is as follows $\square$

Iny $=0.023898 \ln P+0.006304 \operatorname{lnGDP}-0.006651 \ln E P G+0.058895 \ln E P+0.037602 \ln C E+10.235879$

where, P: Total urban population, GDP: Gross Domestic Product, EPG: Energy consumption per unit of GDP, EP: Urban per capita energy consumption, $\mathrm{CE}$ : Proportion of clean energy in end energy consumption.

The results show that the coefficient of determination R2 (multiple R-squared) is 0.9984 and 0.9950 after correction. The model has high goodness of fit and the model is established.

From the analysis, the result is from large to small in order of their influence: per capita energy consumption, proportion of clean energy in energy terminal consumption, total population, energy consumption per unit of gross product and total population.

\subsection{Statistical analysis of clean energy power production by climate division}

According to CHINA ENERGY STATISTICAL YEARBOOK 2018[29], the data changes of clean energy in the past three years from 2015 to 2017 in China's primary energy production are deeply explored. Specifically, it includes national power generation, nuclear power, wind power, solar photovoltaic power generation, and natural gas 
production. Data maps and Line charts are provided to explore the advantages of clean energy resources in various regions, providing support for the next step of alternative application of clean energy in existing urban residential areas.

Electricity generation in each region shows an upward trend year by year. It ranks from high to low as region, hot summer and cold winter region, severe cold region, hot summer and warm winter region and temperate region. Power generation in cold area is the highest, and the average electricity generation in cold region is 2.7 times higher than that in temperate region.

In recent three years, hydropower generation in various regions has tended to grow slowly and steadily. In cold region, hot summer and cold winter region, and severe cold region, hydropower generation is more developed than that in other regions. Yunnan and Sichuan province are located in the upper reaches of the Yangtze River Basin with huge terrain drop, this geographical advantage makes the hydropower development of the two provinces the best.

Nuclear power generation is mainly concentrated in coastal provinces, including Liaoning, Jiangsu, Zhejiang, Fujian, Guangdong, Guangxi and Hainan. From the perspective of climate zoning, nuclear power generation is the most abundant in the hot summer and warm winter region, with an increase of 73.3\% from 2015 to 2017.

Wind power generation is mainly concentrated in Inner Mongolia, Xinjiang, Gansu, Ningxia, Hebei, Liaoning, Yunnan and other regions. From the perspective of climate zoning, the wind power generation is the most abundant in severe cold region, from 2015 to 2017, the wind power generation in severe cold region increased by $45.8 \%$.

Inner Mongolia, Xinjiang, Gansu, Ningxia and Qinghai are major provinces of solar power generation. From the perspective of climate division, solar energy resources are abundant in severe cold region and cold region, and from 2015 to 2017, the solar power generation capacity in the cold region increased significantly, with an increase of $261.9 \%$ compared with 2015 .

From Fig. $3-12$ to Fig. $3-19$, it can be seen that: 1 ) the nuclear power generation capacity in hot summer and warm winter region is ahead of other regions, and the power generation capacity is increasing year by year; 2 ) the wind power generation and solar power generation capacity are strong in severe cold region and cold region, and the power generation capacity is also increasing year by year; 3 ) the clean energy power generation in each region accounts for a small proportion of the total power generation; 4) the clean energy power generation in each region is positively related to the total power generation.

From Fig. 3-8 and Fig. 3-19, areas with natural gas supply exceeding $150 \times 108$ m3 in 2017 include Sichuan, Guangdong, Jiangsu and Beijing. Among them, energy departments in Sichuan Province encourage urban residential buildings to use multi-complementary mode of consumption, such as natural gas preferential price can be reduced to $2.2 \sim 2.3$ yuan/m3. Natural gas supply in each region shows an upward trend year by year. Natural gas supply in each region ranks from high to low as cold area, cold area, hot summer and cold winter area, hot summer and warm winter region and temperate region; natural gas supply in cold region is the absolute advantage. 


\section{Conclusions}

The proportion of clean energy in end-use consumption is increasing year by year. Clean energy technology is a continuous promotion project at home and abroad. The proportion of clean energy consumption also reflects the level of national energy technology. At the same time, clean energy plays a vital role in reducing carbon emissions.

1) In this regression analysis, the proportion of clean energy in the end consumption of energy is added as the influencing factor. The fitting results show that this factor accounts for a large and significant proportion in the influencing factors of existing urban residential buildings, which means that the utilization technology of clean energy will be a very important direction for the transformation of existing urban residential areas. Previous data analysis shows that with the increase of GDP and energy consumption per capita, the energy consumption of urban residential buildings increases year by year. Compared with 2009, the energy consumption of urban residential buildings increases by $43.6 \%$ in 2016. Natural gas-based clean energy has also increased from 7.9$13.4 \%$. But still cannot meet the demand of energy consumption of urban residential.

2) The highest proportion of fitting results and significant influencing factors are per capita energy consumption. The residential energy consumption behavior has a great influence on the energy consumption of building operation, and the superposition effect is huge. In this respect, energy-saving and emission reduction are reflected in the continuous renewal of energy-saving science and technology and the conscientious practice of people's energy-saving concept.

3) The geographical distribution of resources in each climate zone is obvious. The energy-saving transformation of existing urban housing should comprehensively predict the growth proportion of clean energy in different regions from the perspective of the energy substitution system coupled with the superior resources of clean energy and the environmental benefits of clean energy, so as to meet the energy consumption demand of cities and towns.

4) Put forward the planning framework of clean energy upgrading and transformation system of existing urban residential areas in China, combined with the professional development of clean energy and above existing urban residential building energy consumption, clean heat source application status in China. The project team next step, according to the climate characteristics, energy resources, building types, use rules, control performance of existing urban residential areas, according to the original energy saving and local conditions Then, the specific clean energy alternatives of existing residential areas in typical cities should be reasonably determined.

\section{Declarations}

\section{Author Contributions:}

Conceptualization, Li Zhao.; methodology, Wei Chen. investigation, Qiong Li; writing-original draft preparation, Wei Chen.; writing-review and editing, Qiong Li.; visualization, Li Zhao. All authors have read and agreed to the published version of the manuscript. 


\section{Funding:}

This research was funded by National key research and development plan funding (2018YFC0704800).

\section{Conflicts of Interest:}

The authors declare no conflict of interest. The funders had no role in the design of the study; in the collection, analyses, or interpretation of data; in the writing of the manuscript, or in the decision to publish the results.

\section{References}

1. Xu Shichun, Xi Rong, he zhengxia,2012. Influencing factors of carbon emissions from energy consumption in China and policy implications. Resource science. 2012,34 (01): 2-12

2. Liu Boyuan,2019. On the current problems and Strategies of urban planning management in China. Real estate, 2019 (18): 35

3. Wang QingQin, fan Dongye, Zhao Li, Wu Weiwei, Qiu Liping, Meng Chong,2019. Development survey and research focus on upgrading of existing urban residential areas. Engineering construction 2019 (06): 75-78.

4. NDRC,2017a. National Energy Administration. Revolutionary strategy of energy production and consumption $₫ 2016-2030 \rrbracket$. Beijing: China

5. MOHURD, AQSIQ,2015. Assessment standard for green retrofitting of existing building. Beijing: China.

6. MOHURD, 2016. Technical code for the retrofitting of existing residential building on using function. Beijing: China

7. MOHURD, 2017.Technical standard for green retrofitting of existing community. Beijing: China.

8. CABR, 2017.Technical specification for green retrofitting of existing building. Beijing: China.

9. Beijing housing and Urban Rural Development Commission,2016. Technical Specification for Energy Efficient Renovation of Existing Residential buildings. Beijing China

10. Dutta R, 2019. Use of Clean, Renewable and Alternative Energies in Mitigation of Greenhouse Gases. Reference Module in Materials Science and Materials Engineering.

11. Authority, G.L,2007. Action Today to Protect Tomorrow: The Mayor's Climate Change Action Plan. London: England.

12. Greater London Authority (GLA),2010. The draft climate change adaptation strategy for London. London: England

13. Love Ekenberg, Karin Hansson, Mats Danielson, \& Göran Cars, 2017. A Low Carbon Society by 2050: The Stockholm-Mälar Region Case. Deliberation, Representation, Equity: Research Approaches, Tools and Algorithms for Participatory Processes.

14. Scarlatoiu G,2012. Low Carbon, Green Growth Korea.Korean Science and Technology in an International Perspective. Physica-Verlag HD, 2012.

15. Meibom P, Hilger K B, Madsen H, et al, 2013. Energy Comes Together in Denmark: The Key to a Future Fossil-Free Danish Power System. IEEE Power \& Energy Magazine, 2013, 11(5):46-55. 
16. Qun Ding, Wenjia Cai, Can Wang, Mukul Sanwal, 2017. The relationships between household consumption activities and energy consumption in china- An input-output analysis from the lifestyle perspective, Applied Energy, Volume 207,2017, 520-532.

17. Xiaoli Zhao, Na Li,Chun, bo Ma,2012. Residential energy consumption in urban China: A decomposition analysis. Energy Policy,2012,41.

18. MOHURD,2011. The planning method and practice of energy-saving reconstruction of existing urban residential buildings. China Construction Industry Press, Beijing.

19. Jiang Yi, 2016. Thinking about the concept of building energy conservation in China. China Construction Industry Press, Beijing.

20. Shan Hu, Da Yan,Siyue Guo,Ying Cui,Bing Dong, 2017. A survey on energy consumption and energy usage behavior of households and residential building in urban China. Energy \& Buildings,2017,148

21. Vance L, Eason T, Cabezas H,2015. Energy sustainability: consumption, efficiency, and environmental impact. Clean Technologies \& Environmental Policy.2015,17(07):1-12.

22. Ren Hong, Chen Yongqi, Cai Weiguang, Wang Xia, Deng Yingpeng,2017. Urban architecture in Chongqing Based on STIRPAT model Analysis on Influencing Factors of energy consumption. HVAC, 2017,47 (11): $40-$ $44+20$

23. Cui Z, Liu X,2013. Urban building energy consumption forecast based on the IPAT theory. Advanced Materials Research, 689:482-486.

24. Dietz T, Rosa EA,1997. Effects of Population and Affluence on CO2 Emissions. Proceedings of the National Academy of Sciences, 1997,94冈10冈:175- 179.

25. Richard York, Eugene A. Rosa, Thomas Dietz,2003. STIRPAT, IPAT and Impact:analytic tools for unpacking the driving forces of environmental impacts. Ecological Economics 46 (2003):351-365.

26. Tahmassebi A, Gandomi A H,2018. Building energy consumption forecast using multi-objective genetic programming. Measurement, 2018, 118:164-171.

27. NDRC, 2017b. 13th Five-Year plan for renewable energy development. Beijing: China.

28. CABR,2018. Retrofitting of Existing Buildings Yearbook of 2018. Beijing: China.

29. Department of energy statistics, National Bureau of Statistics, 2019.CHINA ENERGY STATISTICAL YEARBOOK 2018. China Statistics Press, Beijing.

30. MOHURD,2019. Statistical yearbook of urban and rural construction in China 2018. Beijing: China

31. CABEE,2012-2018.2012-2018 Annual Research Report on China's Building Energy Consumption. Beijing: China.

\section{Figures}




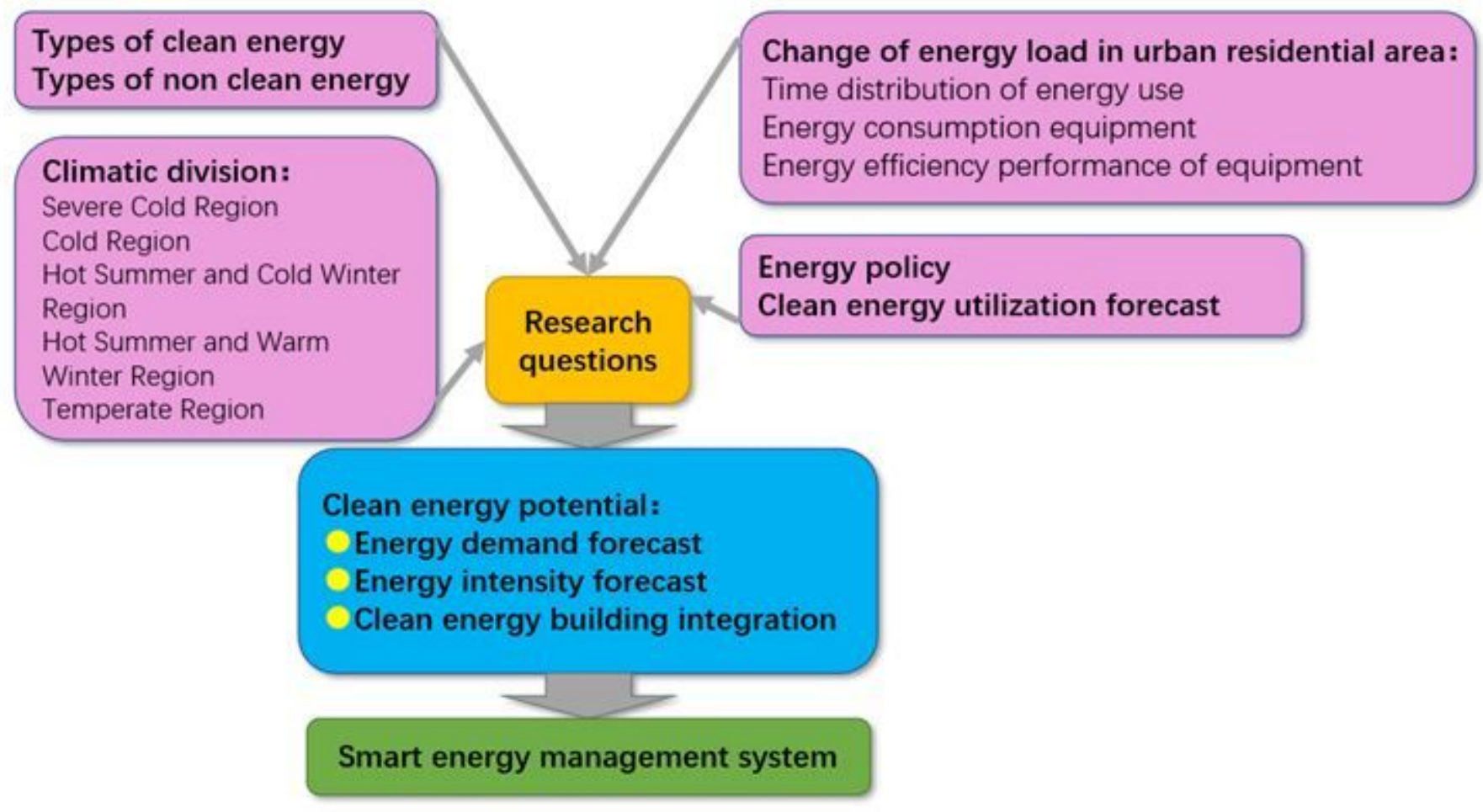

\section{Figure 1}

Survey and research process

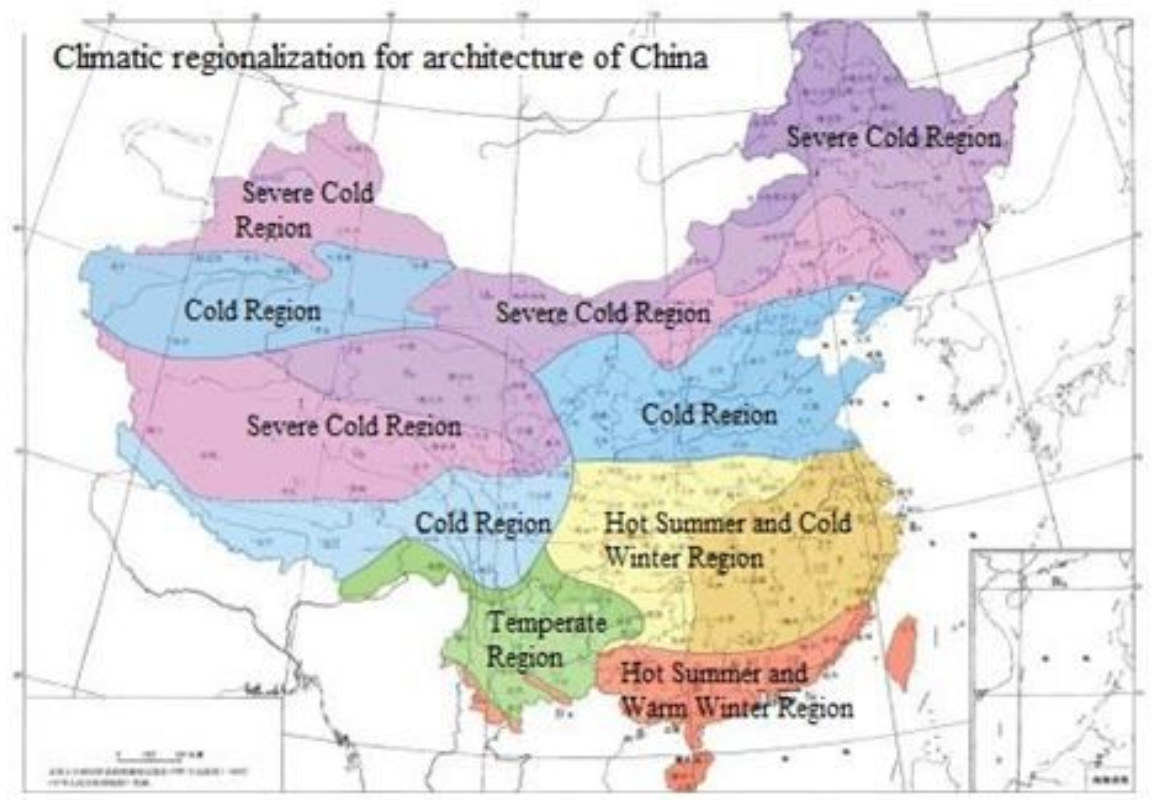

\section{Figure 2}

Climatic regionalization for architecture of China. Note: The designations employed and the presentation of the material on this map do not imply the expression of any opinion whatsoever on the part of Research Square concerning the legal status of any country, territory, city or area or of its authorities, or concerning the delimitation of its frontiers or boundaries. This map has been provided by the authors. 


\section{Reconstruction area of existing urban buildings}

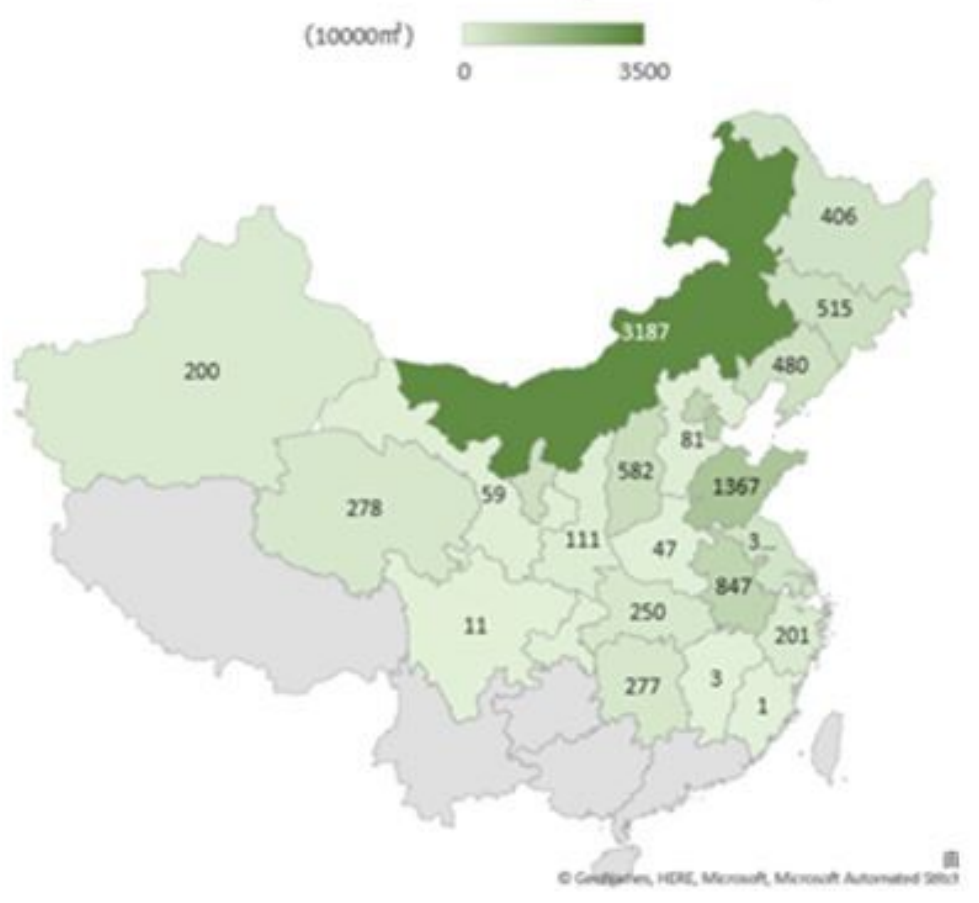

Figure 3

2017-2018 cumulative energy-saving reconstruction area of urban existing residential buildings in China. Note: The designations employed and the presentation of the material on this map do not imply the expression of any opinion whatsoever on the part of Research Square concerning the legal status of any country, territory, city or area or of its authorities, or concerning the delimitation of its frontiers or boundaries. This map has been provided by the authors.

Renewable energy demonstration building project

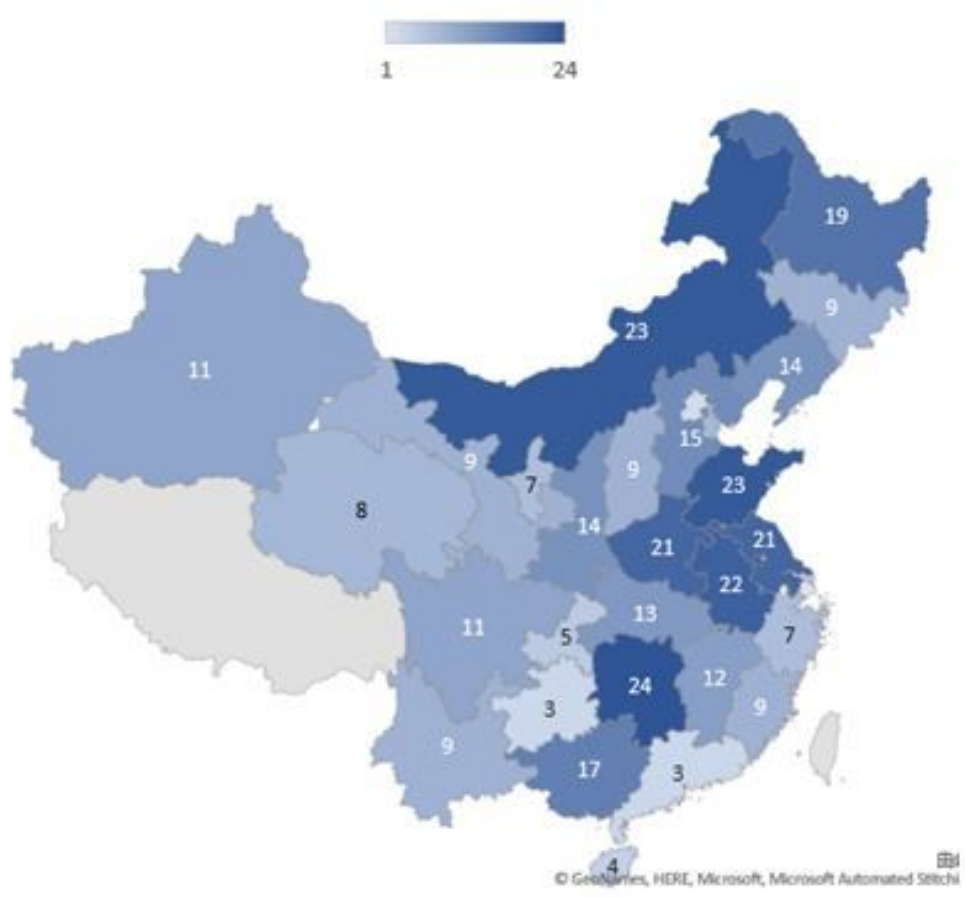


Figure 4

Number of renewable energy application demonstration projects in each province in 2018. Note: The designations employed and the presentation of the material on this map do not imply the expression of any opinion whatsoever on the part of Research Square concerning the legal status of any country, territory, city or area or of its authorities, or concerning the delimitation of its frontiers or boundaries. This map has been provided by the authors.

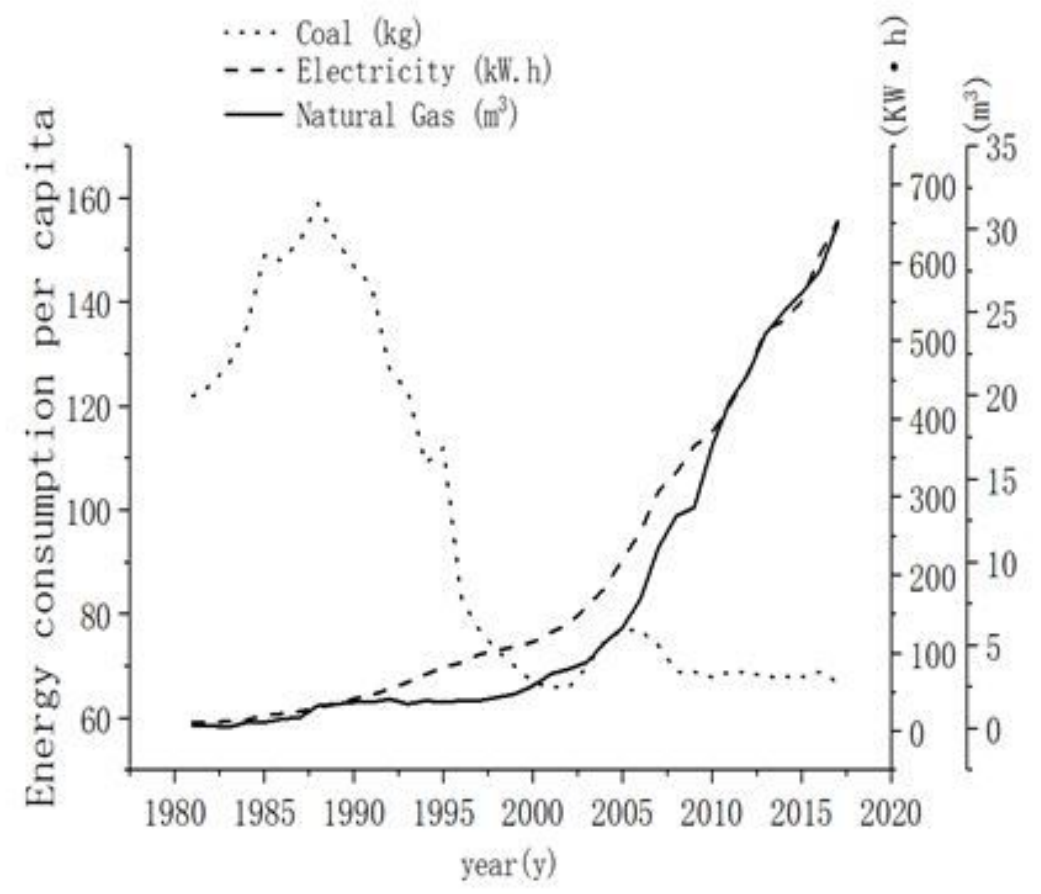

Figure 5

Per capita use of different types of energy 


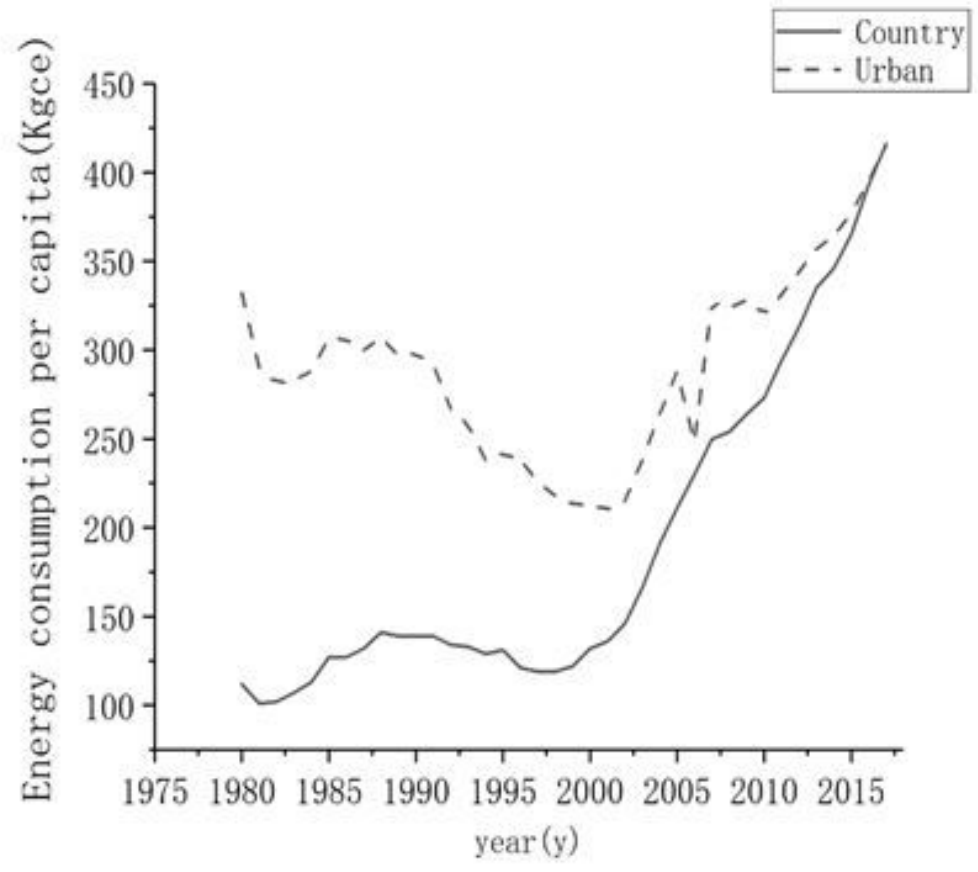

Figure 6

Country and Urban per capita energy use

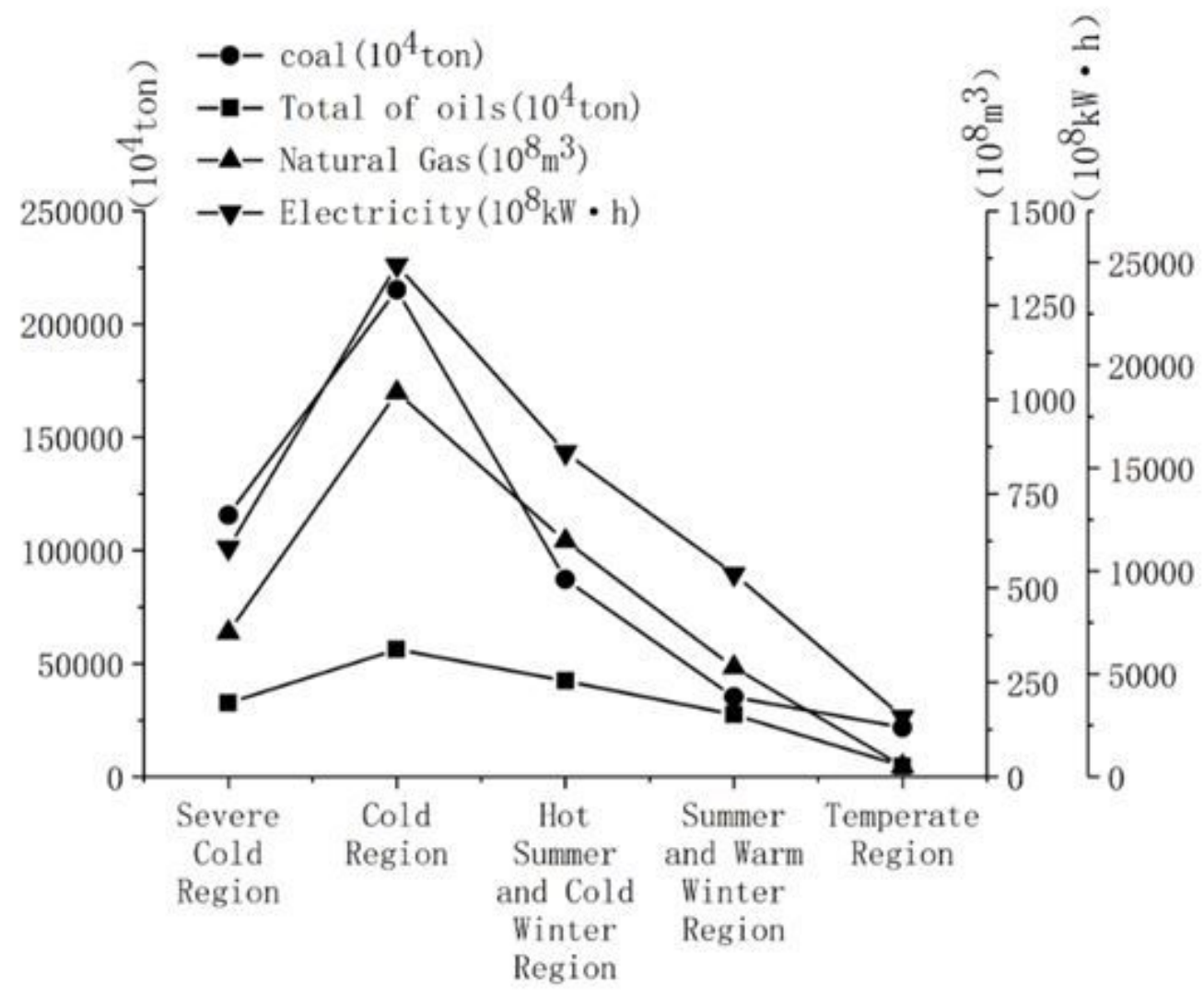


Figure 7

Different energy consumption in different climate region

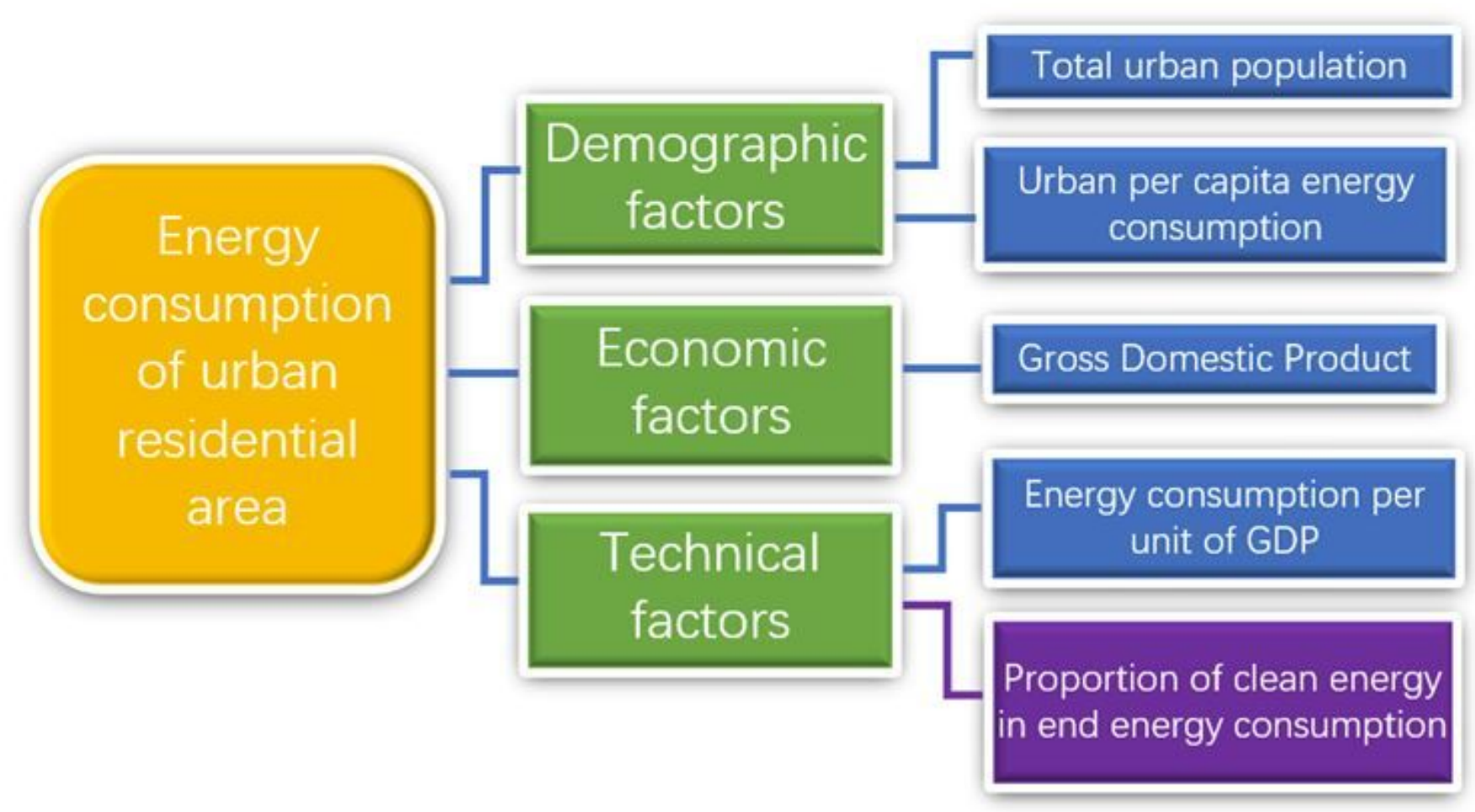

Figure 8

energy consumption model of urban buildings 
RIDGE TRACE

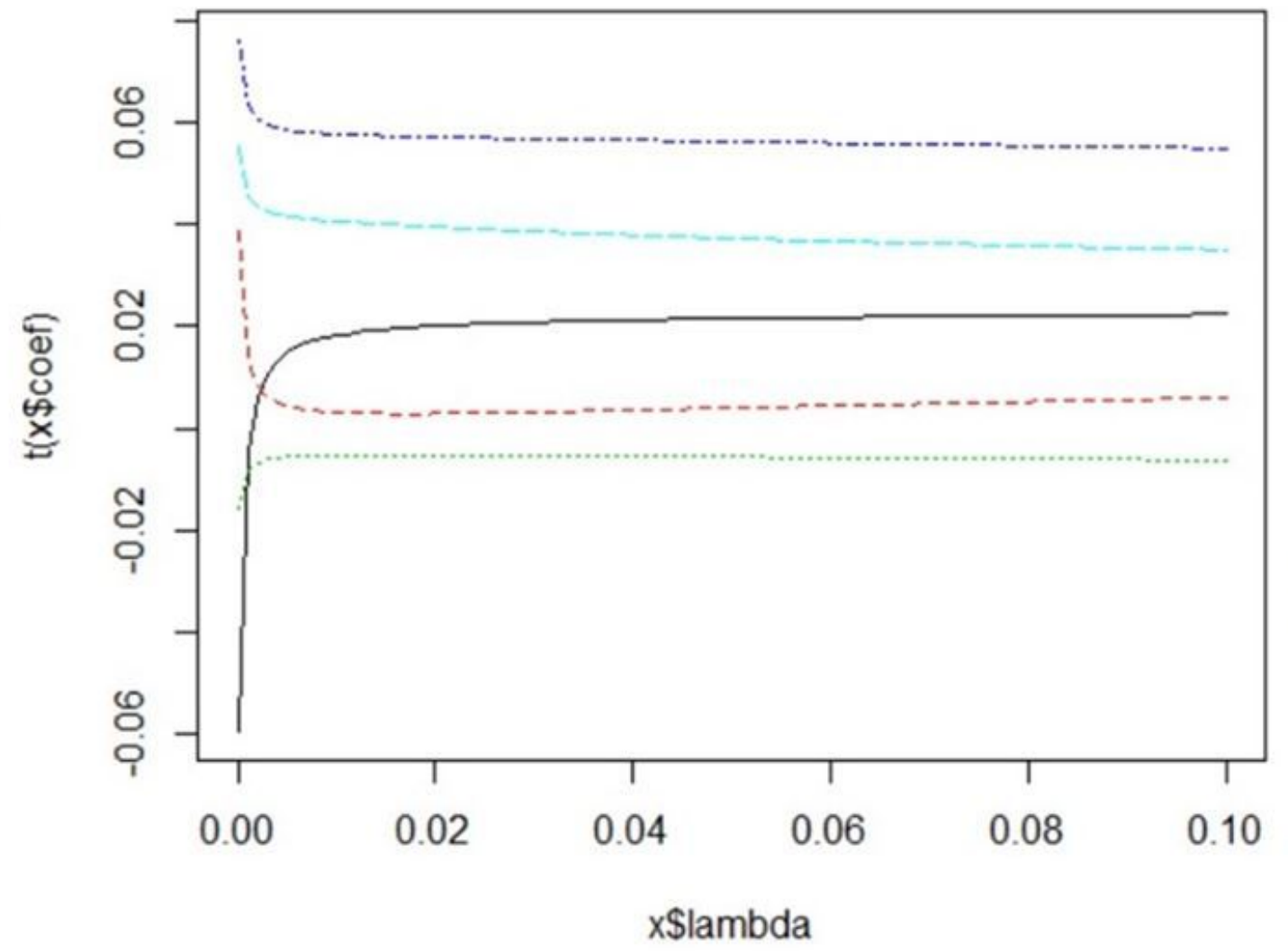

$\mathrm{x}$ \$coef:regression coefficient x\$lambda:Ridge parameters

- EP

C CE

- $\mathrm{P}$

- GDP

- EPG

\section{Figure 9}

RIDGE TRACE(EP: Urban per capita energy consumption, CE: Proportion of clean energy in end energy consumption, P: Total urban population, GDP: Gross Domestic Product, EPG: Energy consumption per unit of GDP) 


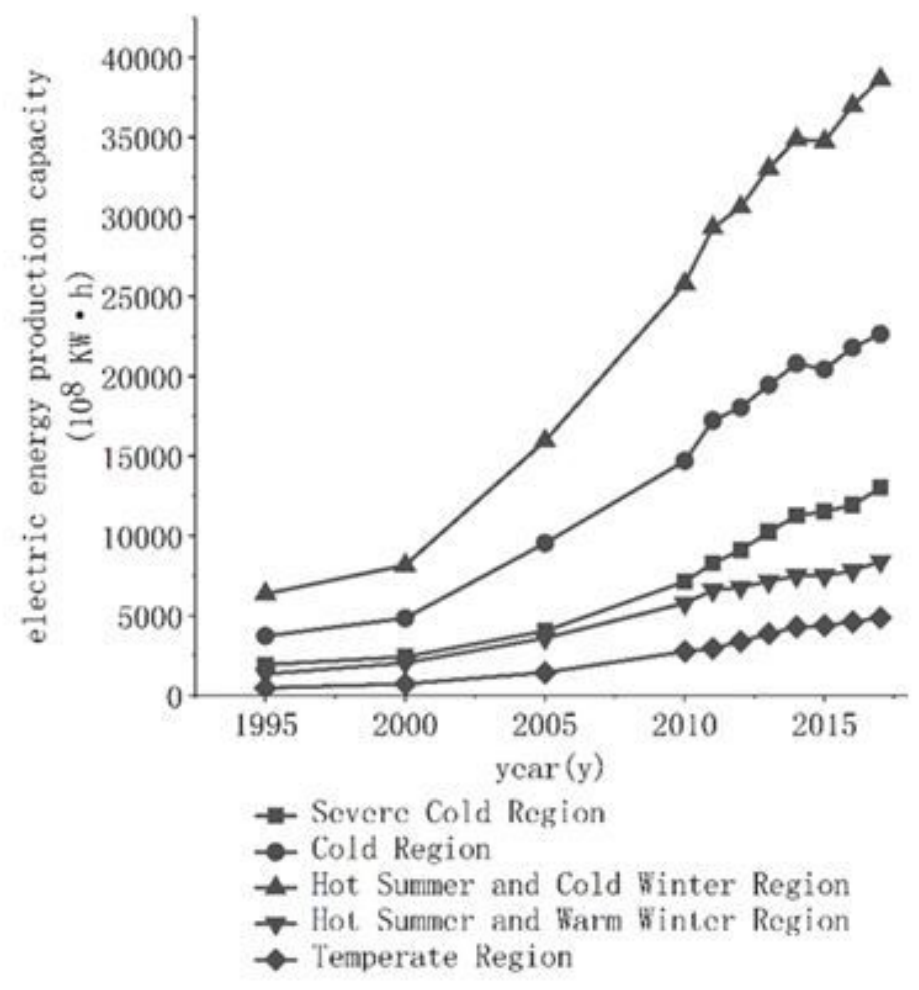

Figure 10

Power generation by region

Electric energy production capacity of 2017

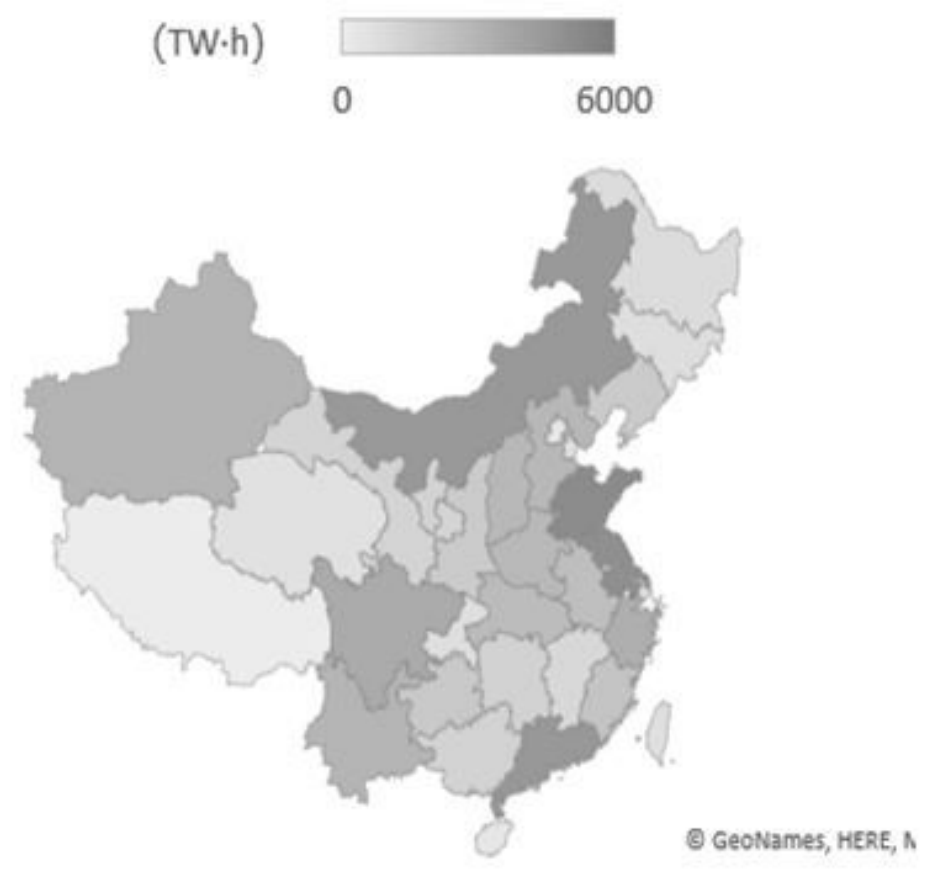

Figure 11 
Electric energy production capacity of 2017

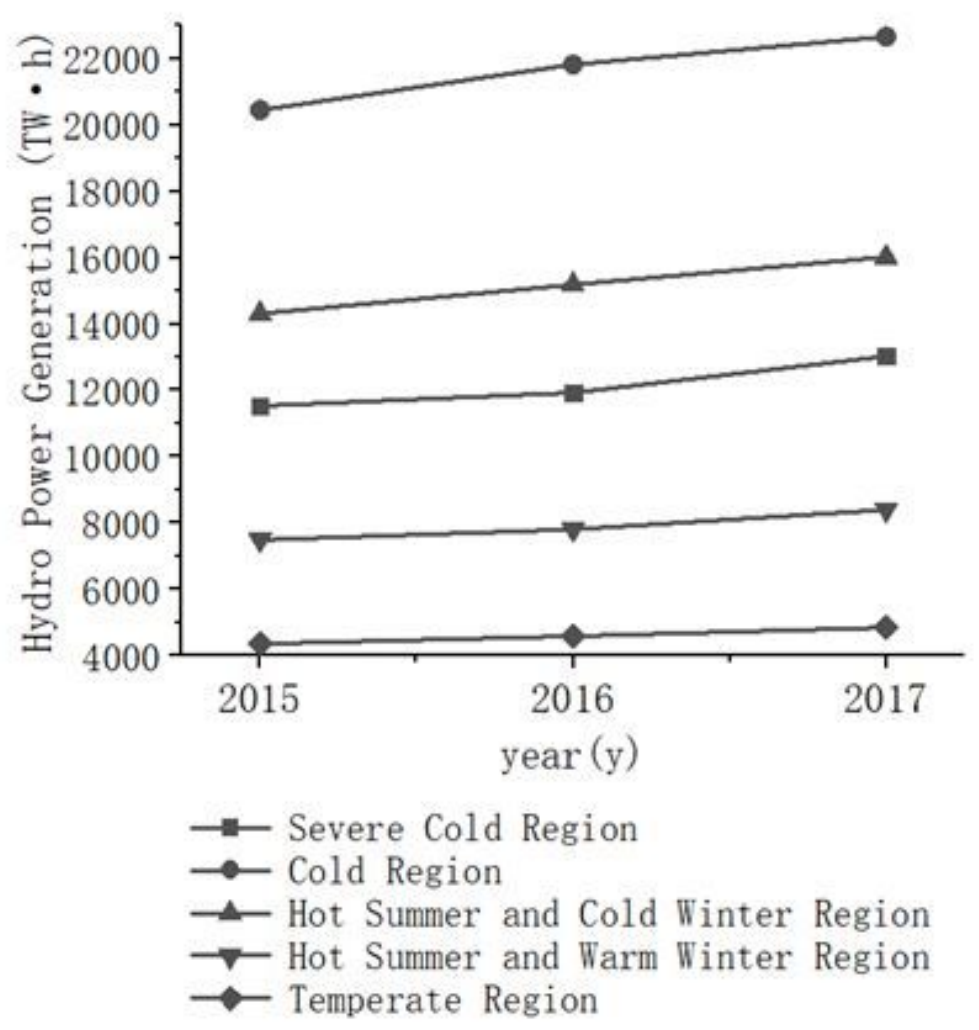

\section{Figure 12}

Hydropower generation by region 


\section{Hydropower generation of 2017}

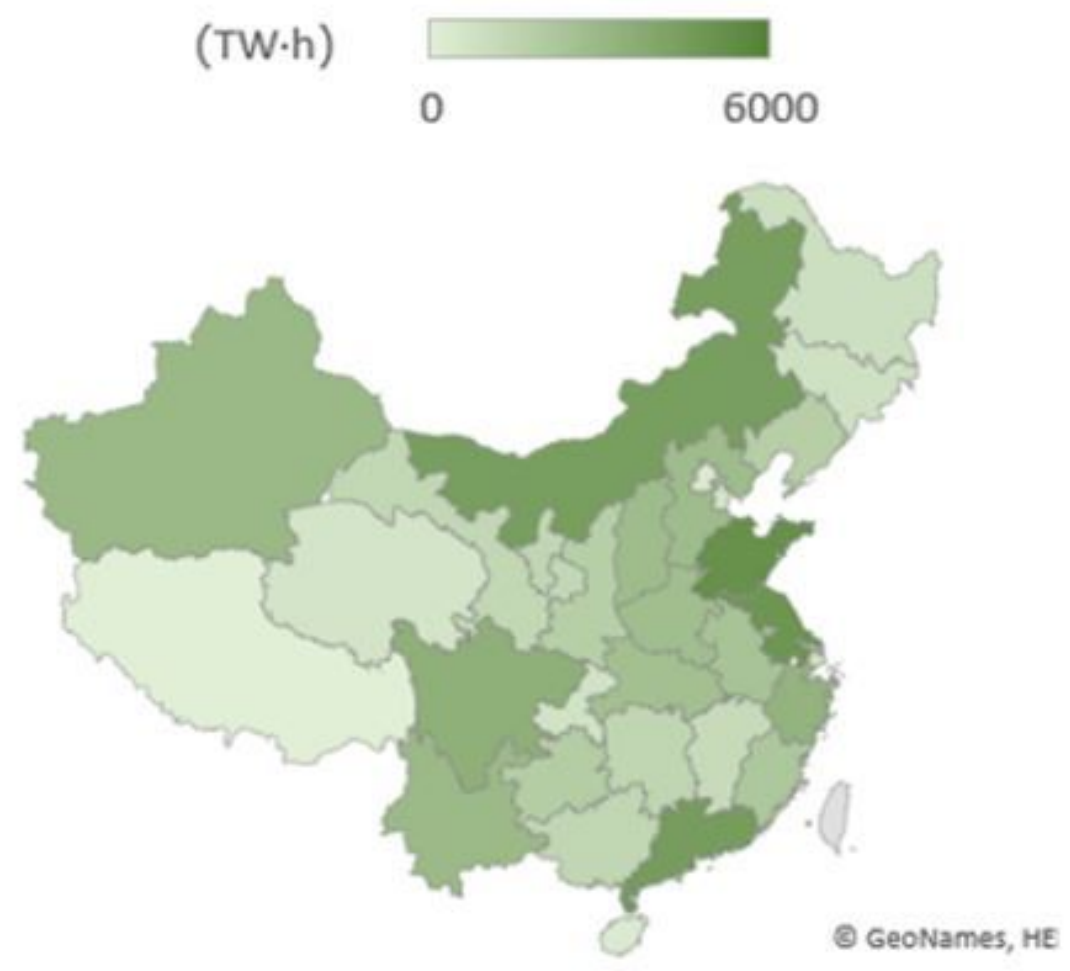

Figure 13

Hydro Power Generation of 2017. Note: The designations employed and the presentation of the material on this map do not imply the expression of any opinion whatsoever on the part of Research Square concerning the legal status of any country, territory, city or area or of its authorities, or concerning the delimitation of its frontiers or boundaries. This map has been provided by the authors. 


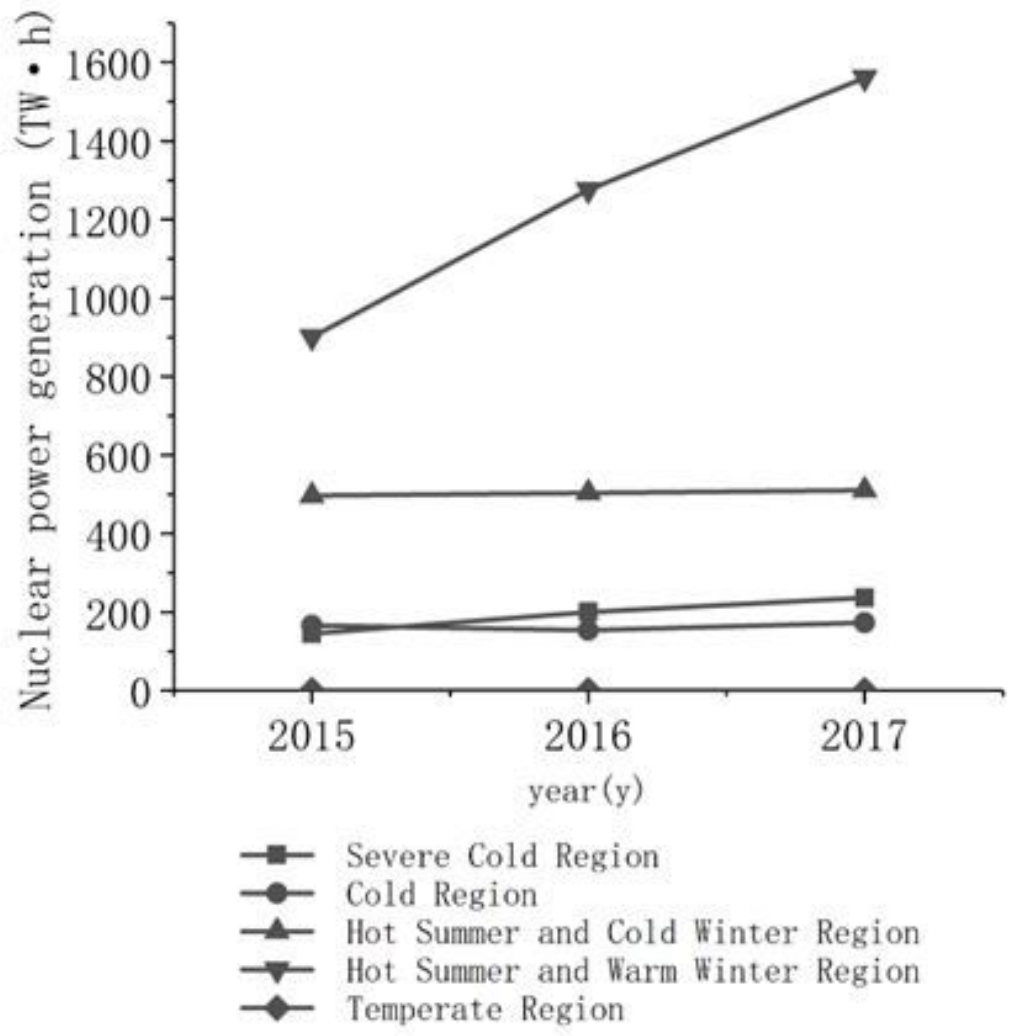

Figure 14

Nuclear power generation by region 


\section{Nuclear power generation of 2017}

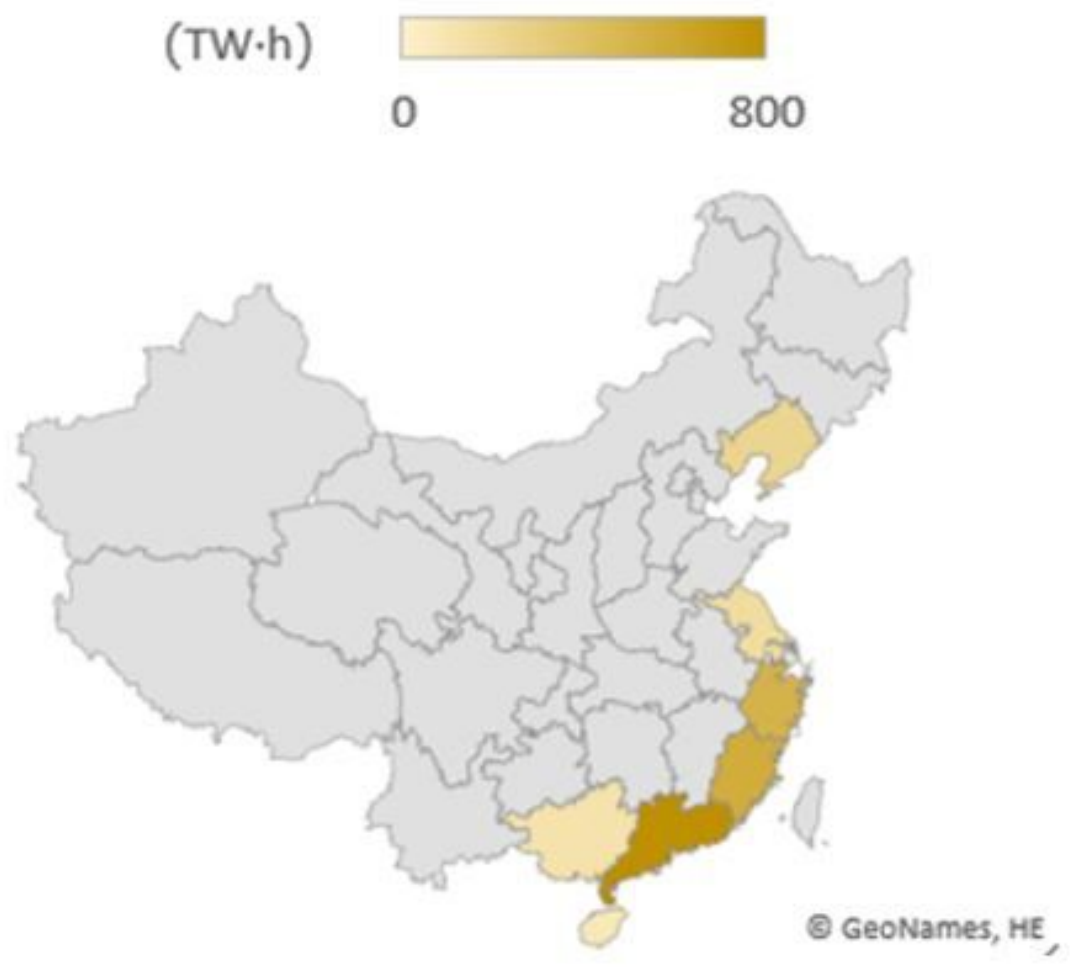

\section{Figure 15}

Nuclear power generation of 2017. Note: The designations employed and the presentation of the material on this map do not imply the expression of any opinion whatsoever on the part of Research Square concerning the legal status of any country, territory, city or area or of its authorities, or concerning the delimitation of its frontiers or boundaries. This map has been provided by the authors. 


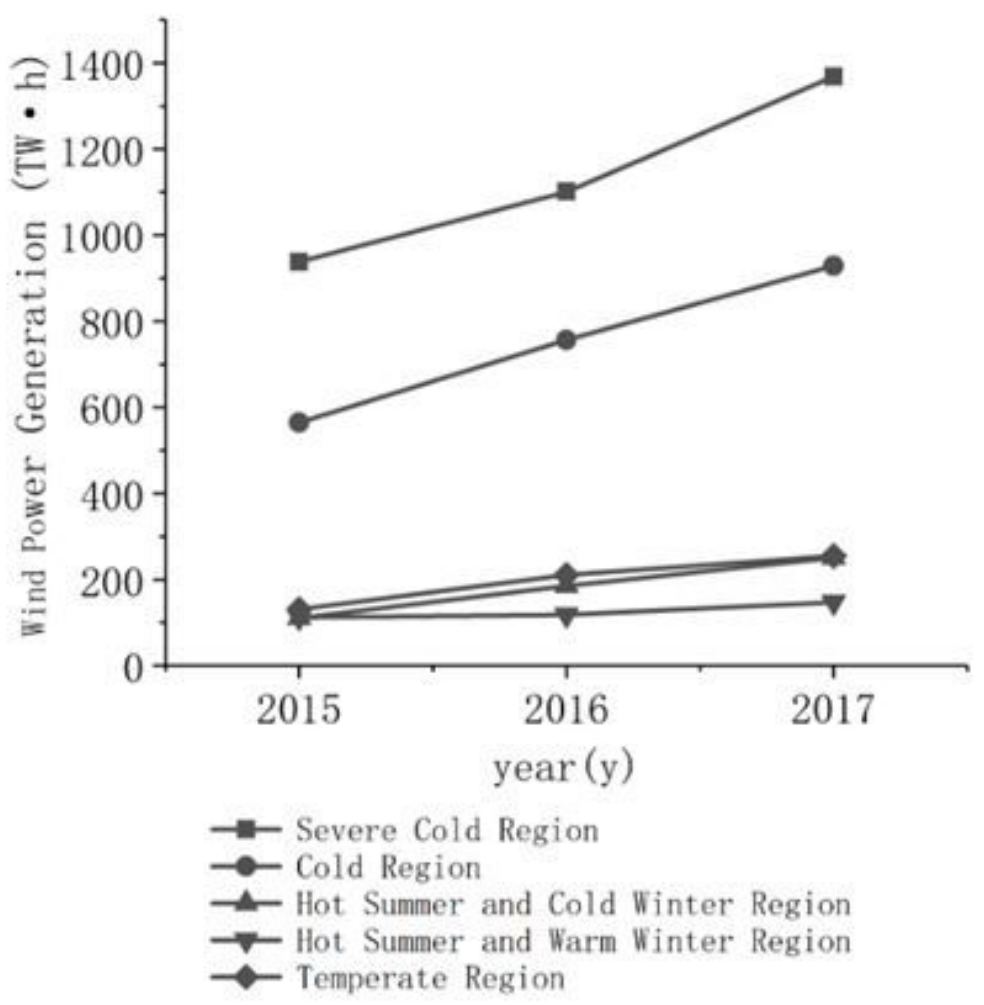

Figure 16

Wind power generation by region

\section{Wind power generation of 2017}

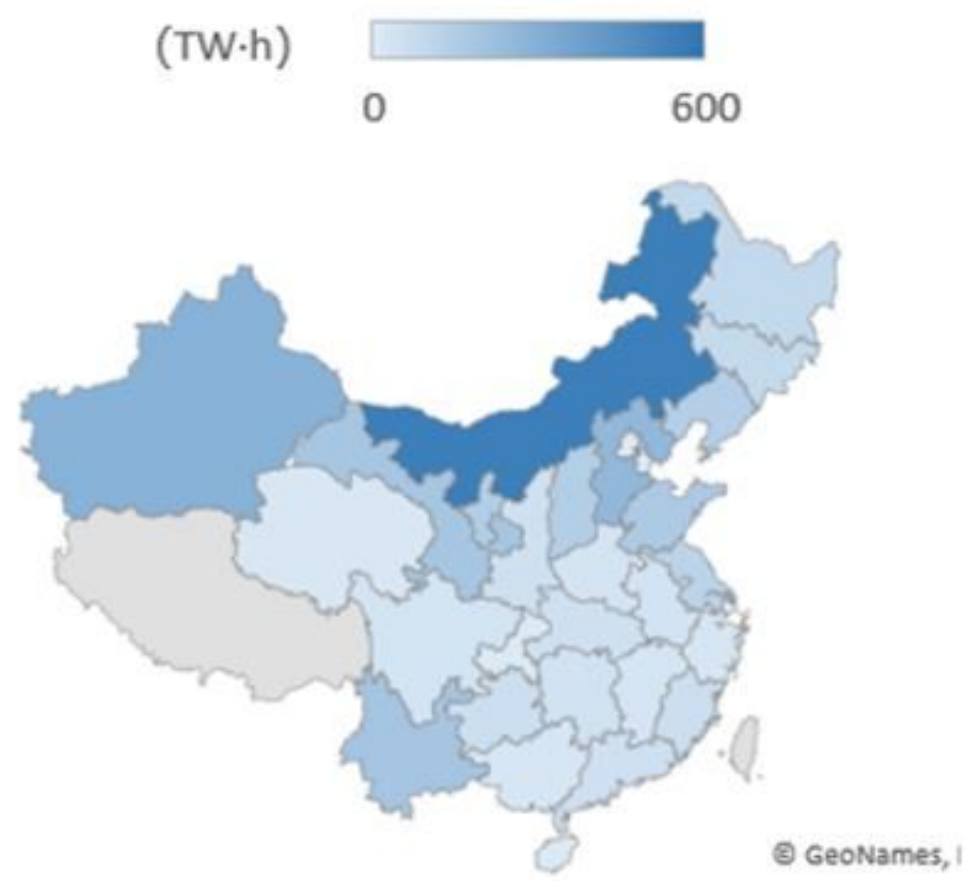

Figure 17 
Wind Power Generation of 2017. Note: The designations employed and the presentation of the material on this map do not imply the expression of any opinion whatsoever on the part of Research Square concerning the legal status of any country, territory, city or area or of its authorities, or concerning the delimitation of its frontiers or boundaries. This map has been provided by the authors.

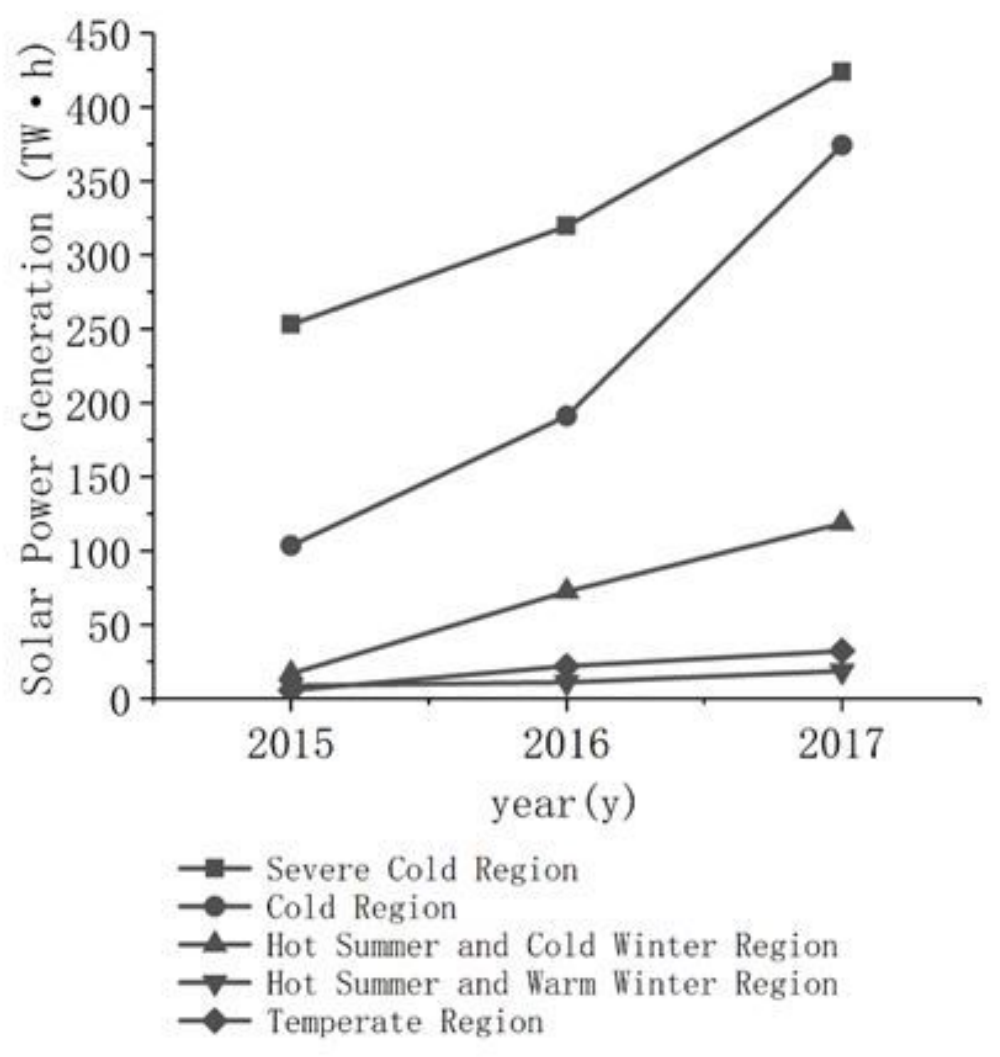

\section{Figure 18}

Solar power generation by region 


\section{Solar power generation of 2017}

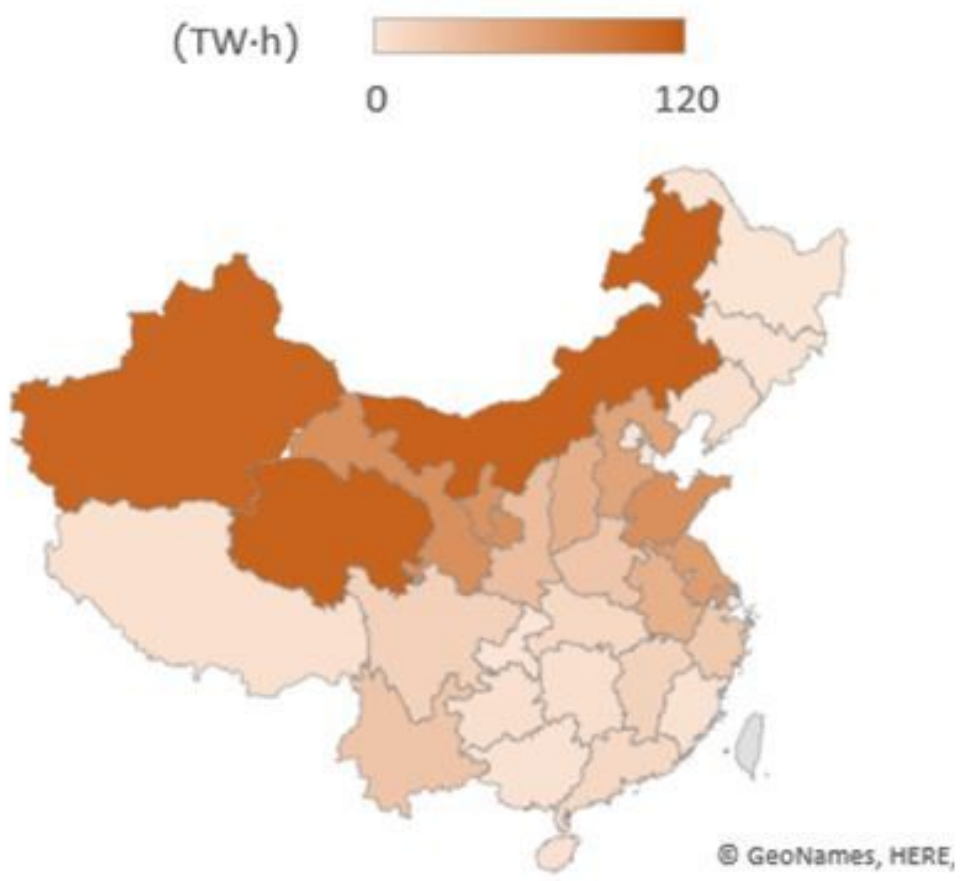

Figure 19

Solar Power Generation of 2017. Note: The designations employed and the presentation of the material on this map do not imply the expression of any opinion whatsoever on the part of Research Square concerning the legal status of any country, territory, city or area or of its authorities, or concerning the delimitation of its frontiers or boundaries. This map has been provided by the authors. 


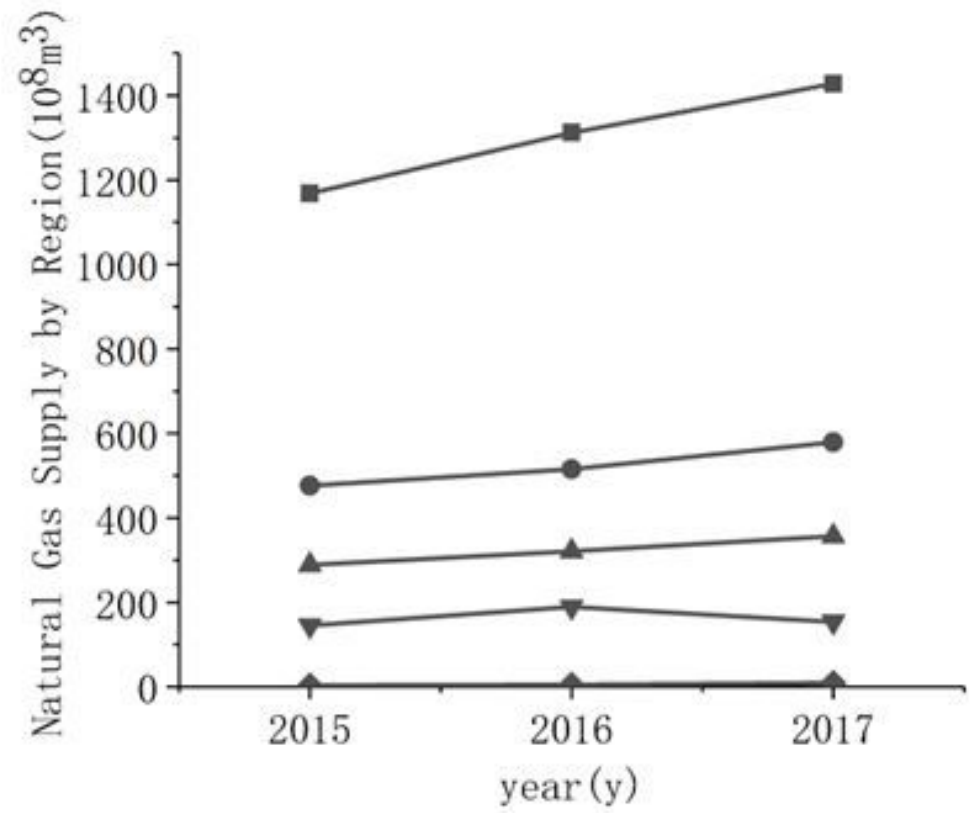

\section{Figure 20}

Natural Gas Supply by region

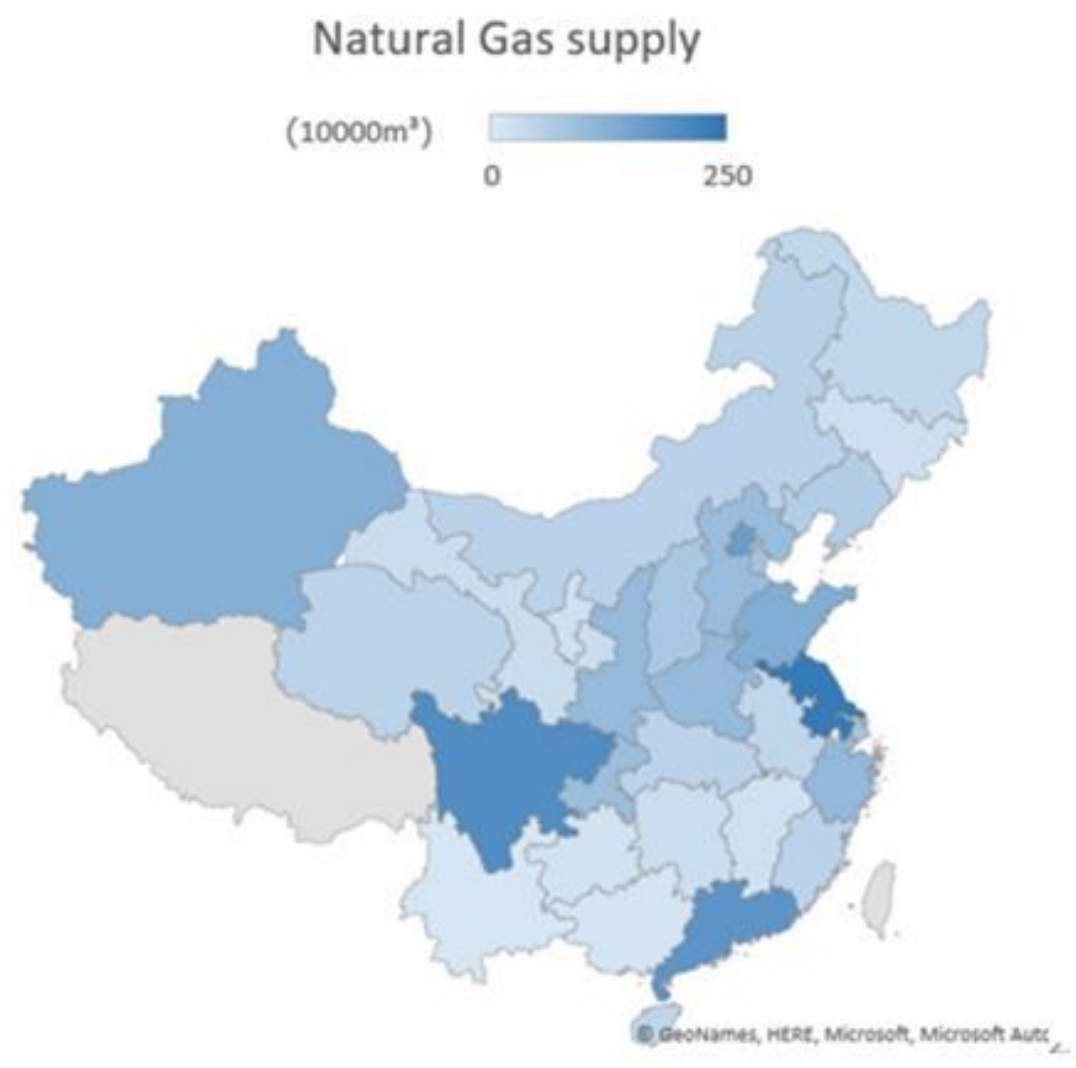




\section{Figure 21}

Natural Gas Supply. Note: The designations employed and the presentation of the material on this map do not imply the expression of any opinion whatsoever on the part of Research Square concerning the legal status of any country, territory, city or area or of its authorities, or concerning the delimitation of its frontiers or boundaries. This map has been provided by the authors. 